\section{ANTIRETROVIRAL THERAPY AND INTESTINAL MICROSPORIDIOSIS IN THAI HIV INFECTED PATIENTS}

\author{
WIWANITKIT V.*
}

Sir,

Intestinal parasite infection, which is also one of the basic health problems in tropical region, is common in the HIV infected patients in tropical countries. The lack of sufficient antiretroviral therapy is mentioned among those patients (Wiwanitkit, 2001). In Thailand, human microsporidiosis has been sporadically reported since its first documentation (Pitisuttithum et al., 1995). In the HIV area, the microsporidiosis became an important opportunistic infection among HIV-infected patients (Wiwanitkit, 2001). Wanke et al. reported that the prevalence of microsporidiosis among Thai HIV-infected patients presenting with diarrhea was about $4.2 \%$ (Wanke et al., 1999).

Luckily, the access for antiretroviral therapy among Thai HIV infected patients increases in a recent few years due to the in-country production of antiretroviral drugs. We report herein the prevalence of microsporidiosis in Thai HIV seropositive patients in a period when antiretroviral therapy was easily available. In this work, microsporidiosis occurrence was determined in HIV+ patients assisted in a Thai sexually transmitted diseases clinic, King Chulalongkorn Memorial Hospital, in period from January 2003 to December 2005. All works were ethically approved and performed under informed consent principles. In order to research, 500 patients, carriers of diarrhea or not, were appraised. The samples of feces were collected and sent for further examination for Microscoporidia at the Parasitology laboratory. The results verified only four positive samples $(0.8 \%)$. The whole microsporidiosis cases were from the group of naive case without previous history of antiretroviral drug therapy $(n=42)$ while those who were in the antiretroviral therapy program $(n=458)$ had no infection. According to this study, the infection rate in the group without previous antiretroviral therapy is $9.5 \%(95 \%, \mathrm{CI}=3 \%-22 \%)$. The rate of microsporidiosis is statistical significant higher among the group without antiretroviral drug therapy ( $Z$ test, p value $<0.01)$.

Of interest, the prevalence of microsporidiosis in this study is lower than the previous reports in Thailand, in the same area, in the period when antiretroviral drug was hard to access (1.6\%) (Wiwanitkit, 2001). The increasing immunity due to the use of antiretroviral drugs might be an important factor for prevention of opportunistic infections among our HIV-infected patients.

\section{REFERENCES}

Pitisuttithum P., Phiboonnakit B., Chindanond D., PunpoonwONG B., LeELASUPHASRI S. \& VANiJANOND S. Intestinal microsporidiosis: first reported case in Thailand. Southeast Asian Journal Tropical Medicine Public Health, 1995, 26, 378380.

Wanke C.A., Cohan D., Thummakul T., Jongwuttiwes S., Grayson M.L., Hammer S.M. \& Hanvanich M. Diarrheal disease in patients infected with human immunodeficiency virus in Bangkok, Thailand. American Journal of Tropical Medicine and Hygiene, 1999, 60, 871-874.

WIWANITKIT V. Intestinal parasitic infections in Thai HIV-infected patients with different immunity status. BMC Gastroenterology, 2001, 1, 3.

Reçu le 26 mars 2007 Accepté le 19 juin 2007

* Department of Laboratory Medicine, Faculty of Medicine, Chulalongkorn University, Bangkok Thailand 10330. 